THÉMATA. Revista de Filosofía

No51, Enero-junio (2015) pp.: 247-270

ISSN: 0212-8365 e-ISSN: 2253-900X

doi: 10.12795/themata.2015.i51.13

\title{
VIDA COTIDIANA, ARTESANÍA Y ARTE
}

\author{
EVERYDAY LIFE, HANDICRAFT AND ART
}

\author{
Adolfo León Grisales Vargas ${ }^{1}$ \\ Universidad de Caldas, Manizales (Colombia)
}

Recibido: 07-04-2014

Aceptado: 21-09-2014

Resumen: En este artículo se intenta mostrar que, por lo general, ha habido una concepción negativa y equivocada de la artesanía, derivada del carácter paradigmático que se le habría reconocido al arte y de la manera como se suele entender la vida cotidiana, casi siempre como algo deficiente y pobre que debe ser trascendido. En este trabajo se estudian diversos enfoques de la filosofía y las ciencias sociales; en el primer caso se han revisado, fundamentalmente, las ideas de Heidegger, Collingwood, Gadamer y Danto; en el segundo, los planteamientos de algunos teóricos del diseño industrial, sobre todo Dorfles y Aicher, así como los de algunos sociólogos y antropólogos, en especial, Hauser, Francastel, Bourdieu, Clifford Geertz, Canclini y Lauer. Y, por último, para proponer una rectificación de la mirada en torno a la artesanía, se ha buscado desconectarla del modelo del arte para verla desde el horizonte de sus vínculos esenciales con el mito; en este caso se ha acudido al apoyo de algunos filósofos que se han ocupado de los temas del mito y de la cultura, particularmente de Blumenberg.

Palabras-clave: Estética filosófica, artesanía, diseño, arte popular, cotidianidad, mito.

Abstract: This article tries to show that, in general, there has been a negative and misguided conception of handicrafts, derived from paradigmatic character that would have been recognized to art and how as is usually understood everyday life, often as something deficient and poor to be transcended. In this paper we study various approaches of philosophy and social sciences, in the first case were

[1] (adolfo.grisales@ucaldas.edu.co) Doctor en filosofía de la Universidad Javeriana. Vinculado al Departamento de Filosofía de la Universidad de Caldas en las áreas de estética, hermenéutica y epistemología de las ciencias humanas y sociales. Publicaciones recientes: (2014) "El arte como forma esencial del olvido" (En: El arte y la fragilidad de la memoria. Universidad de Antioquia); (2011) "Diseño y artesanía: acerca de la racionalidad de la técnica" (Revista Arquetipo, \# 2); (2011) "La experiencia originaria de lo otro: una mirada hermenéutica" (Revista Culturas y Drogas \# 18); (2010) "El arte otra vez como tejne" (Revista de Diseño Kepes \# 6). 
reviewed, mainly the ideas of Heidegger, Collingwood, Gadamer and Danto, the second, some theoretical approaches of industrial design on all Dorfles and Aicher, as well as some sociologists and anthropologists, particularly Hauser, Francastel, Bourdieu, Clifford Geertz, Canclini and Lauer. And finally, to propose a correction of the look around the handicrafts, has been sought disconnect art pattern to see it from the horizon of its essential links with the myth, in this case has come to the support of some philosophers that have dealt with the themes of myth and culture, particularly Blumenberg.

Key-words: Philosophical aesthetics, handicraft, industrial design's, folk art, everyday life, myth.

\section{Introducción}

En este artículo, antes que proponerme argumentar de manera exhaustiva alguna tesis en particular, quiero ofrecer una serie de reflexiones, espero que provocativas, en torno a la manera como se habría pensado y valorado la artesanía en relación con el arte. El hilo conductor sobre el que plantea dicha relación, y podría decirse que es en cierto modo la tesis general a la que apunto, es que habríamos malentendido la artesanía por haberla pensado en función del arte, de modo negativo. Lo que afirmo es que el fondo de ese menosprecio por la artesanía es la manera como en general, en la cultura occidental, se ha menospreciado también la vida cotidiana. Todo esto a su vez estaría conectado con la manera como en Occidente se ha idealizado el afuera y se ha visto con cierta indiferencia el adentro: el arte es asociado a lo trascendente, a lo espiritual, a la idea, al afuera de la caverna; la artesanía en cambio es asociada con lo intrascendente, con lo mundano, con lo meramente sensible (y placentero), con el interior de la caverna. Así, mientras el arte se asocia al museo, a la catedral y a los espacios públicos, la artesanía se asocia a los espacios íntimos de la casa y al cuerpo.

Por lo general, ha habido una concepción negativa y equivocada de la artesanía, derivada del modo despectivo como se suele entender la vida cotidiana y de la manera como se piensa la relación entre artesanía y arte, donde este último tendría un carácter paradigmático. La tensión y oposición entre arte y artesanía está determinada en buena medida por dos factores: uno, la manera como se habría escrito la historia del arte desde el Renacimiento y el sentido que se le habría dado en esta historia a la dimensión técnica; y dos, el relativo olvido en el que habría caído la cuestión del vínculo íntimo entre el arte y los espacios o lugares que ocupa. En tal sentido, las supuestas limitaciones de la artesanía, y la marca de su falta de espiritualidad, se habrían pensado como dadas sobre todo por su irremediable dimensión técnica y por su arraigo esencial a los lugares o espacios en los que se inscribe. Lo que quiero argumentar no es tanto que la artesanía también sea con toda legitimidad arte (sería un camino estéril), sino que es necesario encontrar 
categorías que permitan pensarla desde ella misma y no en función del arte; y, también, que es por el camino de esas supuestas limitaciones que se puede reivindicar su sentido y su dimensión espiritual.

Apoyado en los enfoques de la metaforología de H. Blumenberg y de la hermenéutica simbólica, propongo pensar la singularidad de la artesanía desde una íntima relación con el mito y en función de su conexión esencial con el espacio. El arte, y pese a lo que nos dice Heidegger, que el arte espacia, en realidad en la historia occidental se puede caracterizar por el hecho de que "abandona la casa", se desarraiga del territorio, se hace "universal", la artesanía en cambio es parte fundacional de la casa, del territorio propio, y es precisamente el trabajo de las manos el que logra romper la continuidad absoluta del espacio, y así lo funda, de modo que sólo hay espacio como tal en tanto éste es "puesto" por la construcción de la casa, el hogar.

\section{I.}

El concepto de artesanía, en su acepción más amplia y frecuente, suele hacer referencia a un saber-hacer mecánico y repetitivo carente de creatividad y a un tipo de objetos utilitarios producidos de un modo premoderno. Sin embargo, hoy lo más usual es entenderlo en relación con un tipo de objetos, hechos a mano, que tienen una dimensión estética y una carga de identidad cultural, como los que se comercian en las "Ferias de Artesanías" y están destinados fundamentalmente a la decoración ${ }^{2}$. En este último sentido la artesanía goza de reconocimiento social y aprecio; pero ese prestigio ya no es evidente si nos desplazamos a un plano teórico, en el que por lo general se la comprende y valora en términos negativos o, en el mejor de los casos, se resuelve elevarla al estatus de arte, con lo que se liquida la pregunta por su especificidad.

[2] Artesanías de Colombia la define como: "Actividad de transformación para la producción creativa de objetos finales individualizados (productos específicos que cumplen una función utilitaria y tienden a adquirir el carácter de obras de arte; actividad que se realiza a través de la estructura funcional e imprescindible de los oficios y sus líneas de producción, que se llevan a cabo en pequeños talleres con baja división social del trabajo y el predominio de la aplicación de la energía humana física y mental, generalmente complementada con herramientas y máquinas relativamente simples; actividad que es condicionada por el medio geográfico, que constituye la principal fuente de materias primas, y por el desarrollo histórico del marco sociocultural donde se desarrolla y al cual contribuye a caracterizar" (Herrera, 1996: 9). Para Artesanías del Perú: "Un conjunto de actividades que concurren a la transformación de unos bienes por otros nuevos, mediante un proceso de producción caracterizado por la prioritaria presencia de sub-procesos tipificados por el predominio del ingenio y la habilidad manual sobre el efecto transformador de las máquinas y las herramientas, por una limitada división técnica del trabajo y por una agregación del valor predominantemente atribuible al trabajo humano vivo" (Lauer, 1982: 76). Debo aclarar que recojo estas dos definiciones sólo como representativas de la manera en la que se suele pensar hoy la artesanía, pero no las propongo como las definiciones a las que nos habremos de acoger en este artículo.

THÉMATA. Revista de Filosofía, $\mathrm{N}^{\circ} 51$ enero-junio (2015) pp.: 247-270

doi: 10.12795/themata.2015.i51.13 
Es frecuente que la crítica de arte descalifique una obra diciendo que es mera artesanía, y ello quiere decir o bien que es puro virtuosismo vacío, carente de espíritu, o que se trata de una obra que no trasciende lo meramente local y costumbrista. Buena parte de los filósofos modernos se refieren a la artesanía sólo como límite negativo, para designar algo que no es arte aunque puede llegar a confundirse con él. Es por el lado de las ciencias sociales donde podemos encontrar unos estudios más positivos y enriquecedores sobre el tema ${ }^{3}$, pero casi siempre ha ocurrido que o bien se la ha reducido a objeto etnográfico o se la ha querido reivindicar como arte, en ocasiones con el argumento de que el concepto de arte es eurocéntrico y responde a una visión colonialista que desconoce el arte de otros pueblos o, en la misma línea de P. Bourdieu (1988), se ha dicho que la distinción entre arte y artesanía no se sustenta en algún rasgo ontológico o fenomenológico, sino que se trata de un mecanismo de poder para preservar la estratificación social. En cualquiera de estos casos la artesanía en su especificidad se pierde.

Hay otro ámbito teórico particularmente importante donde nos encontramos el concepto de artesanía jugando un papel de contraste distinto: el diseño industrial. Desde esta perspectiva se han visto el trabajo y la producción artesanal como un modo preindustrial de elaboración de utensilios. De nuevo se habrá de tomar la artesanía como un punto negativo de referencia y oposición: frente a la descomposición analítica del proceso de producción, en el que se diferencian el diseño y la producción, en el que se objetiva y racionaliza el concepto de funcionalidad, y la belleza se reduce a lo puramente formal, accesorio y ornamental, la artesanía pasa a ser caracterizada como un modo irracional de producción, en el que se entremezclan el diseño y la producción, los factores emotivos y los objetivos, la funcionalidad y la belleza ${ }^{4}$.

Tal vez, respecto de la Bauhaus la situación es ambigua, porque si bien es cierto que, por una parte, se toma como referente el taller del artesano en relación con la formación del diseñador, por otra parte sus pretensiones ideológicas más profundas se ubican del lado del arte. Lo que se persigue es algo así como una humanización de la técnica por el camino de su reconciliación con el arte, y esto conducirá a absurdos tales como querer hacer de un objeto eminentemente funcional, como una silla, una obra de arte, un objeto que entonces

[3] Al respecto cabe destacar, entre otros, a Mirko Lauer, a Néstor García Canclini, a Clifford Geertz, a James Clifford, a Pierre Francastel y a Pierre Bourdieu; incluso E. Gombrich le dedicó uno de sus más importante libros, El sentido del orden, aunque limitado a un matiz formal: los patterns o modelos decorativos.

[4] Gillo Dorfles es particularmente duro al respecto, cuando propone considerar al diseño industrial como el verdadero arte apropiado a las condiciones contemporáneas, precisamente en tanto que prescinde de esa, dirá, dimensión irracional del arte del pasado; posición en muy buena medida cercana a la que en el campo de la arquitectura sostuviera Adolf Loos en su conocida polémica contra el ornamento considerado como un delito.(Véase: Dorfles, 1977 y Loos, 1972).

THÉMATA. Revista de Filosofía, No51 enero-junio (2015) pp.: 247-270 doi: 10.12795/themata.2015.i51.13 
debe ser soportado por su noble condición de obra de arte, aunque desafíe lo más elemental del saber práctico y del verdadero uso de las sillas ${ }^{5}$.

En todo caso, también desde la teoría del diseño la artesanía en su esencia pertenece al pasado; y ello no se ve negado, sino antes confirmado por la singular situación que se está dando en Latinoamérica, donde artesanía y diseño parecen estarse reconciliando; pero es claro que lo que se da aquí no es propiamente un diálogo, sino algo similar a lo que sucedió en la época de las primeras vanguardias, cuando artistas como Picasso volvieron sus ojos a la plástica de los pueblos no occidentales y vieron allí un rico depósito de formas, aprovechable para darle un nuevo vigor al arte occidental ${ }^{6}$.

En suma, puede decirse que ha sido muy pobre o hasta inexistente la reflexión sobre la artesanía ${ }^{7}$ como tal, la encontramos por lo general en relación con algo más, ya sea con el arte o con el diseño industrial. Su sentido negativo se ha tomado como obvio y como punto de partida seguro para pensar un concepto nuevo, el de arte, para el que la modernidad no disponía de otro lenguaje ni de otros referentes que los que podía tomar prestados de la artesanía; o se la ha tomado como un modo irracional de producción de objetos de uso, precisamente en tanto no diferencia los elementos estéticos de los funcionales.

\section{II.}

Dado que en Latinoamérica y en los pueblos no occidentales buena parte de la producción plástica se ha jugado del lado de la artesanía, y de que la mayor parte de la historia del arte ha estado marcada por la indistinción, es necesario preguntar si la artesanía en efecto agota su ser en la negatividad y si no será posible comprenderla desde ella misma. Ya R. Collingwood (1960) había advertido que toda la teoría moderna sobre el arte había estado enredada en una confusión al querer pensar el arte desde "una teoría técnica" o una teoría artesanal del arte, pero tal vez el problema no radica, como él piensa,

[5] La escuela alemana de diseño Ulm, con Otl Aicher, Tomás Maldonado, Yves Zimmerman, entre otros, se habrá de distanciar de la ideología de la Bauhaus justamente en el punto relativo a la relación entre diseño y arte, pero a esta discusión haremos referencia más adelante (Véase: Aicher, 2001 y 1994).

[6] La situación que se presenta en Latinoamérica en realidad es un poco más compleja tal como nos lo muestran Mirko Lauer y Néstor García Canclini, dado que se presenta una singular tensión entre tradición y modernidad; pese a todo, y a la enorme valoración que ha ganado en nuestro medio la artesanía, subsiste respecto de ella una cierta conciencia de "atraso" (Véase Lauer, 1982 y Canclini, 2001).

[7] Recientemente ha habido una creciente preocupación por la artesanía, por la estética de la cotidianidad y en general por la vida cotidiana, parte de esa nueva bibliografía no alcancé a tenerla en cuenta para este artículo debido a que apenas la he venido descubriendo cuando ya concluía esta investigación. Lo que afirmo sobre la casi inexistencia de reflexión en torno a la artesanía se refiere sobre todo a los teóricos clásicos de la estética y las teorías del arte.

THÉMATA. Revista de Filosofía, Nº51 enero-junio (2015) pp.: 247-270 doi: 10.12795/themata.2015.i51.13 
en haber cargado el lastre de un significado arcaico que ha devenido impropio, sino en no haber comprendido que artesanía y arte son inconmensurables desde todo punto de vista y que, por ello, lo que acontece en el Renacimiento es la creación de algo enteramente nuevo, así que de entrada se malentiende el propio arte si se lo quiere ver como una superación de la artesanía.

Considero que el arte no es en realidad un "después" de la artesanía, que no hay un hilo de continuidad que lleve de la una a la otra, que el arte no es una superación de la artesanía, sino algo completamente distinto de ella. Se ha pensado que el destino supremo del artesano es devenir artista, pero ¿es realmente eso lo que quiere decir Miguel Ángel cuando afirma que él no es un artesano, o es eso a lo que se refiere Leonardo cuando se ve a sí mismo como un hombre de ciencia? Y ni siquiera hoy, cuando por fin se ha hecho patente la inesencialidad del oficio para el $\operatorname{arte}^{8}$, se ha vuelto a recoger la pregunta en torno a la supuesta ruptura entre arte y artesanía en el Renacimiento, y tampoco se ha visto tal ruptura en relación con ese otro punto decisivo de la época que fue el Humanismo. Así, por ejemplo, y en contra de E. Panofsky, tal vez se pudiera pensar que el encuentro entre arte y Humanismo no fue sólo un encuentro tardío ${ }^{9}$, cuyo punto nodal son las interpretaciones de Marsilio Ficino sobre la obra de Platón, sino que más bien ambos brotaron de un mismo impulso que ya se hace evidente desde cuando Cennini recomendaba a sus discípulos atenerse a la percepción, con lo que se comenzaba a quebrar la gran teoría de la mímesis que, como es sabido, no se restringía a las artes, sino que tenía implicaciones filosóficas y teológicas profundas (Tatarkiewickz, 1991).

$\mathrm{El}$ artista, en efecto, se puede definir como alguien que ya no es artesano, o que piensa de sí mismo que es algo más que un artesano, pero de ahí no se desprende que el artesano es alguien que quiere llegar a ser artista, o que piensa de sí que es algo menos que un artista. ¿Por qué dar por supuesto que es más acertada la concepción que el artista tiene del artesano que la que éste pudiera tener de sí mismo? ¿Por qué asumir que son más válidas las razones

\footnotetext{
[8] No debe olvidarse que por ejemplo Kant, aunque reconoce al genio como el rasgo distintivo del arte, sostiene luego que, puesto a elegir entre gusto y genio, él se quedaría con el gusto. Pero en el pensamiento contemporáneo, aunque el asunto no se plantea en los términos de la misma disyuntiva kantiana, se ha repetido con insistencia que el oficio (y ello quiere decir a la vez que el gusto y la belleza) resultan inesenciales para el arte, ya encontramos alusiones a esto en Heidegger, en Collingwood y sobre todo en Danto que ha hecho de esta una sus tesis centrales (Véase Danto, 2003: 45-64).

[9] E. Panofsky sostiene que las teorías del arte y el humanismo en el Renacimiento corren paralelos y sólo vienen a confluir tardíamente, casi al final de este período; la tesis que quiero proponer ahora, con el apoyo de Jean Luis Ferrier y de David Summers, es que incluso en relación con el humanismo habría que buscar su impulso y sus raíces en el giro que estaría tomando la gran teoría de la mímesis, particularmente con Cenino Cennini (Véase, Panofsky, 1987; Ferrier, 1975 y Summers, 1993).
}

THÉMATA. Revista de Filosofía, Nº51 enero-junio (2015) pp.: 247-270 doi: 10.12795/themata.2015.i51.13 
del artista para distanciarse del artesano que las que puede tener el artesano para persistir como artesano?

El arte es más bien un "antes" respecto de la ciencia y la filosofía modernas, que un "después" de la artesanía, es decir, que en realidad hay una línea directa entre arte y ciencia moderna, pero que no hay tal línea entre artesanía y arte. No haber aclarado esto nos ha llevado a malentender la artesanía y a encerrarla definitivamente en el pasado; así, cualquier intento por pensarla se considera un anacronismo o una concesión al romanticismo. Podría pues completarse la afirmación de Collingwood diciendo que tampoco hemos comprendido la artesanía por haberla pensado en función del arte (y del diseño industrial).

\section{III.}

El asunto, sin embargo, debe ser puesto en un horizonte más amplio, no se trata sólo del problema más bien especializado de la relación entre arte y artesanía, o de aprehender la verdadera esencia del arte y de la consecuente constatación de la inesencialidad del oficio para el arte, sino de indagar por lo que hay implicado en dicha relación, y tal vez una clave decisiva sea preguntar por eso que se ha dado por obvio y evidente: la devaluación de la vida cotidiana y del modo de racionalidad que le es más propio, el saber práctico. Esto se hace particularmente claro en lo que tiene que ver con uno de los rasgos más importantes para definir la artesanía: el oficio y el trabajo de las manos, en relación con lo cual la artesanía se distancia tanto del arte como del diseño, aunque por razones distintas.

Para el diseño es como si "hecho a mano" quisiera decir "hecho sin pensar", cuando bien pudiera significar que fue "pensado con las manos". A lo sumo, como ocurre con Ruskin (1910), se reivindicará la artesanía como la única modalidad auténtica del ornamento; aunque con Adolf Loos (1972) el ornamento como tal será considerado un "delito", una concesión a la irracionalidad y al derroche. Pero la idea de Ruskin nos permite caer en la cuenta de que el trabajo manual ha devenido en algo cuya justificación es puramente estética y en la misma medida no se le reconoce ninguna dimensión racional o cognitiva (esto nos permite trazar una primera diferencia con el trabajo del obrero, quien entonces no es alguien que en realidad trabaje con sus manos, sino más bien alguien que debe convertirse en algo así como una máquina y acoplarse a la cadena de producción).

El reverso de esta estetización del trabajo manual es una abstracción de los conceptos de racionalidad y funcionalidad, así como del criterio de evaluación de calidad, la perfección. Desde la racionalidad que se impone a partir de la revolución industrial es frecuente que se piense el objeto artesanal como un objeto "imperfecto", pero en tal juicio se evidencia que nos atenemos a un 
concepto de perfección metafísico e idealista, para el que el modelo material y concreto de perfección se encarna en el producto industrial; es decir, es con relación al objeto industrial como se juzga la imperfección de la pieza artesanal, y es como si se asumiera que la prueba definitiva de la imperfección de la artesanía es el hecho de que cada objeto es distinto; mientras que se toma la homogeneidad del objeto industrial como la prueba de su perfección. En tal sentido, la reivindicación que hace Ruskin del trabajo manual, del objeto artesanal, sigue partiendo del reconocimiento de esa "imperfección", que vendría siendo, de un modo romántico, la huella de lo humano, es decir, Ruskin prefiere el ornamento hecho a mano precisamente porque es imperfecto. Se trata pues de una manera apenas formal de entender la "perfección", en la que se suprime todo criterio de contenido, de ahí que el material por excelencia de la producción industrial sea el plástico, una materia inerte y homogénea, cuya singularidad es liquidada de antemano para hacerse susceptible de tomar cualquier forma, mientras que para el artesano cada materia con la que enfrenta su tarea tiene, digamos así, su propio carácter, su propia voluntad, le opone resistencia, lo desafía, de modo que conseguir darle forma constituye un logro por sí mismo.

Otro tanto ocurre con el concepto de funcionalidad, que se suele entender desde el diseño también en términos abstractos, desligado de cualquier determinación subjetiva, cultural o histórica. En contraste, lo que encontramos en el trabajo artesanal y en sus productos es que tanto la funcionalidad como la producción están determinadas por factores subjetivos, culturales, históricos e incluso geográficos. Gillo Dorfles se refiere explícitamente a la artesanía como algo irracional, y el mismo Ruskin, ya viejo, considera que sólo puede florecer en pueblos que todavía viven en un estado de barbarie. Aunque si uno mira la monumental producción de basura de hoy, promovida en buena medida por un diseño industrial al servicio del mantenimiento de un estado irracional de consumo, en el que se producen todo tipo de objetos absurdos, cabe preguntar de qué lado se ubica realmente la racionalidad. Otl Aicher (2001) sostiene que el predominio de una racionalidad restringida a un modo abstracto y metódico de proceder, para la que todo es reducible al cálculo, habría terminado por pervertir la tarea del diseñador, por llevarlo a pensar que la funcionalidad es algo que se puede aislar de las situaciones particulares de uso: "la verdad es el uso" afirma, recogiendo una idea de Wittgenstein; por ello le recomienda al diseño, para recuperar la sensatez, volver los ojos al saber práctico del artesano.

Ya no es escandaloso admitir que, en efecto, el trabajo artesanal está orientado por un saber legítimo, pero entonces se trata de un saber que parece haberse devaluado, y hasta perdido: el saber práctico; un saber que obedece a una racionalidad que atiende a lo singular, a la situación concreta, a la peculiaridad de sus materiales, al uso verdadero de las cosas. Un saber para el que no es pertinente una idea como la de progreso, en el sentido abstracto que ésta tiene con relación al arte, la ciencia y la técnica en la modernidad, y no porque 
el artesano esté limitado por la tradición y carezca de creatividad, sino porque hace sus productos con los ojos puestos en un mercado específico y no con vistas a una anónima y abstracta Historia de la Artesanía. Aunque ello no significa que la artesanía se ubique en las fronteras de la historia, ya por lo menos en lo relativo a la decoración Alois Riegl (1980) y E. Gombrich (1999) nos han mostrado que puede hablarse de una historia; pero ésta no podrá ser pensada igual que la del Arte $^{10}$ y no tiene por qué concluir en el Renacimiento, al contrario, es justo a partir de ahí que se hacen evidentes sus singularidades, ya que antes se diluían merced a la supuesta indistinción entre arte y artesanía.

Para el arte el oficio simplemente ha devenido en algo accidental. Según Danto, ahora, por fin, se ha revelado la verdadera esencia filosófica del arte. Esto quiere decir que el artista no es tanto alguien que "hace cosas", cierto tipo especial de cosas, sino más bien alguien que "dice algo"; que expresa una emoción, dirá Collingwood; que pone en obra la verdad, dirá Heidegger; o que nos propone un juego, un desafío interpretativo, dirá Gadamer.

IV.

El arte se presenta como una especie de promesa de redención frente a la insignificancia y trivialidad de la cotidianidad, así como una manera de superar el limitado horizonte de visión del saber práctico. Y esto es algo sobre lo que se ha reflexionado muy poco en filosofía. Es cierto que a partir de la fenomenología, y mucho más con Heidegger, la filosofía ha vuelto sus ojos a la vida cotidiana y ha mostrado, acertadamente y en contra de la perspectiva epistemológica más propia de la modernidad, que nuestra relación primaria con las cosas y el mundo parte de una comprensión previa, de una interpretación de la realidad que no es temática como tal, pero que es el trasfondo ineludible, no metafísico, sino arraigado en la temporalidad, sobre el que se tiene que asentar cualquier otra tentativa de conocimiento y experiencia de la realidad.

Sin embargo, en este giro, la cotidianidad, a la vez, es mostrada como ese ámbito que en su inmediatez nos oculta el ser, de modo que se requiere de algo así como de una suspensión de tal inmediatez. En el mero usar y trabajar cotidianos las cosas se diluyen en su función, y en ello se diluye nuestra propia existencia, y es sólo en tanto que las cosas se desarraigan de su funcionalidad y nosotros mismos nos desarraigamos de la cotidianidad y del trabajo, como se hace posible y urgente la pregunta por el ser. Se reivindica pues que el saber

[10] La idea de un cierto progreso en el campo del arte ha sido decisiva para que podamos hablar de algo así como una historia del arte o, por lo menos, como dice Danto, de la posibilidad de articular toda la creación artística bajo la idea unificadora de un gran relato, de ahí la importancia que tendría la obra de Vasari (2000), que puede considerarse como modelo y punto de arranque de esa historia, y que justamente apunta a mostrar una historia que habría conducido, por fin, a los logros del Renacimiento.

THÉMATA. Revista de Filosofía, No51 enero-junio (2015) pp.: 247-270

doi: 10.12795/themata.2015.i51.13 
práctico es en efecto un saber, un tipo de visión, y se reivindica el carácter ineludible y primario de la cotidianidad misma; pero, en últimas, se los limita a eso, a lo primario, que debe todavía ser superado y redimido.

Un ejemplo destacado de esto que propongo llamar "el olvido de la cotidianidad" es Heidegger, y es destacado precisamente porque pareciera ser el primero (en realidad el segundo, si incluimos a Husserl) que se habría volcado a pensar la cotidianidad. A lo largo de su obra se pueden encontrar algunos indicios en los que es evidente o bien que tal reivindicación no es lo bastante radical o que oculto sigue habiendo cierto menosprecio por la cotidianidad. En Ser y tiempo (Heidegger, 2003) por ejemplo, se diferencia entre el saber práctico y el teórico, pero el primero se refiere al estar ocupado en un sentido tan amplio que no se le reconoce ninguna especificidad a la maestría en el oficio: da lo mismo el saber del maestro artesano que el uso y el saber cotidiano indiferenciado, en el que las cosas se diluyen en su función. El teórico, en cambio, se considera un "saber-más" en tanto implica un distanciamiento de todo trabajar. En El origen de la obra de arte (Heidegger, 1958) se establece una diferencia radical entre dos modos de existencia, uno más auténtico que otro: el de quienes viven sumergidos en el mero usar, como la campesina, y el de quienes viven en la cercanía de la pregunta por el ser. En La cosa (Heidegger, 1994), se pone todo el énfasis en la libación: los artesanos que moldean la jarra no son incluidos en la "Cuaternidad", y con ello se marca un abismo insalvable entre la producción o el trabajo cotidiano del artesano y el encuentro casi místico entre mortales y dioses, cielo y tierra. Así, pese a la bella descripción que se hace del trabajo del artesano, queda abierta la posibilidad de que la jarra sea simplemente de plástico y no de barro. Al no enfatizarse la dimensión esencial que tienen la producción y el material, pudiera ser que la libación se ofreciera en una neutra, perfecta e ideal jarra de plástico.

También en Collingwood encontramos pistas que nos permiten pensar en este olvido de la cotidianidad. En su ataque a la artesanía incurre en un lugar común de la modernidad: toma la máquina, acríticamente, como modelo para pensar el trabajo humano, y así el artesano se reduce a una máquina imperfecta.

Incluso Gadamer, sin proponérselo, cae en este olvido. Termina por abrir un abismo entre trabajar y festejar; restringe la noción de fiesta a su dimensión ritual y religiosa, y caracteriza negativamente el papel del trabajo respecto de la fundación de la comunidad; se olvida entonces de la fiesta bulliciosa y alegre y de que, con frecuencia, sobre todo en las tareas del campo, el trabajo no aísla, sino que congrega, y que requiere a veces, para ritmar el tiempo, de cantos y de danzas. Se olvida que la fiesta profana es una especie de coronación del trabajo, antes que una ruptura. Toda fiesta es una celebración, la fiesta no acontece sin más, hay que ganarla, merecerla. 
En esa supuesta contraposición entre arte y artesanía se oculta entonces algo más relevante filosóficamente: el contraste entre dos modos de existir. No se trata sólo del tema de la superioridad del arte, ni de la necesidad de que la artesanía se trascienda y devenga en arte, sino, también, de la superioridad de un cierto modo de existencia, de que la inautenticidad y la insignificancia de la cotidianidad se trasciendan y devengan en una modalidad auténtica de la existencia. Y todo ello nos remite a una pregunta decisiva: ¿desde dónde es declarada tal superioridad? ¿Sus argumentos son, digamos así, estrictamente racionales y, en tanto que tales, abstraídos de todo prejuicio o están por el contrario arraigados en algún prejuicio no admitido como tal?

Franz Mayr, en su propuesta de una hermenéutica de la cultura occidental, sostiene que "cabría ofrecer una visión dialéctico-dialógica de la historia cultural de la humanidad dividida entre las categorías matriarcales y las categorías patriarcales" (Mayr, 1989: 13); y en el caso de Occidente lo que se encontraría es que se habría dado una particular tensión en virtud de la cual habría sido predominante el principio masculino y desde allí habría estado decidida previamente, y de un modo no reflexivo, toda posible valoración respecto de la dualidad de las cosas: forma-materia, alma-cuerpo, esencial-accidental, superior-inferior. Y en esa misma línea podríamos decir que el vínculo entre arte y artesanía es también expresión del talante masculino que ha predominado en la cultura occidental, y que se refiere no sólo a la manera como se ha relegado y minusvalorado a las mujeres, sino además a la construcción de toda una filosofía y una concepción de mundo que asocia todos los más altos valores espirituales a los masculino y todo lo más bajo, oscuro, irracional y sensual a lo femenino. No es pues casual, ni exento de implicaciones filosóficas, que haya parecido obvio que el arte sea una ocupación masculina y la artesanía en cambio, más propia de mujeres.

Así pues, históricamente encontramos un vínculo íntimo entre la artesanía, la mujer y la cotidianidad, plagado de prejuicios y de malentendidos que habrían servido para legitimar su desvalorización; de ahí que para entender por qué la artesanía se ha entendido negativamente es necesario preguntarse también por el olvido de la cotidianidad y por la manera como en la cultura occidental se ha relegado a la mujer y se ha asociado todo lo inferior a lo femenino, tanto en un plano político como en el más inmaculado de la filosofía. Es necesario pues ver el tema de la artesanía en el horizonte del arquetipo mítico masculino que marca el derrotero de la cultura occidental: el olvido de Hestia, el centro del hogar; de Gea, la madre Tierra; la "masculinización" de dioses liminares como Artemisa y Hermes; la exaltación de Odiseo como prototipo del nuevo héroe y el relegamiento de Penélope a un segundo plano en razón de su vida rutinaria limitada a tejer y destejer, ocupada "apenas" del cuidado de la 
casa. Por ello cabe sugerir la tesis de que Odiseo y Penélope son la clave mitológica, la metáfora a partir de la cual puede comprenderse lo más fundamental y básico de la existencia humana.

Sin embargo, lo más frecuente ha sido que los intentos por reivindicar a la mujer, a la artesanía y a la cotidianidad, no hagan más que idealizarlas y mantener una oposición abrupta, como ocurre entre los románticos ${ }^{11}$ que mantienen una diferencia radical entre naturaleza y cultura y en sus bellos elogios de la mujer parecieran limitarla a una identificación con la naturaleza, incluso, aunque puesto en términos supuestamente elogiosos, enceguecidas por un saber práctico que las incapacita para las más altas tareas del espíritu; y otro tanto pudiera decirse que ha ocurrido con la reivindicación romántica que se ha hecho del arte popular y del folclor en general. Y conviene señalar esto, porque en efecto es el peligro inmediato al que se enfrenta todo intento de reivindicación como la que ahora se persigue. Puesta esquemáticamente, la pregunta es si será posible reconocer alguna dimensión de verdad en este caso, sin caer en idealizaciones vacías que sólo vengan a reforzar los argumentos de una concepción patriarcal.

Es necesario entonces preguntar si la cotidianidad es apenas lo dado, si la trivialidad es inherente a su definición y está por ello justificada su marginalidad, si ha devenido como tal sólo en razón de que se ha creído justificado verla en relación con un cierto ideal del que sería su trasfondo o si, por el contrario, constituye como tal un logro, un altísimo logro, no simplemente algo inevitable y un trasfondo que siempre podremos dar por supuesto, sino un reto permanente, un desafío constitutivo de la existencia humana y de la historia.

Ahora bien, esa supuesta insignificancia de la cotidianidad deja de parecer evidente si se niega la línea de continuidad entre artesanía y arte, y si a su vez estamos dispuestos a negar la línea de continuidad entre saber práctico y saber teórico o entre una vida supuestamente anestesiada en la cotidianidad, extraviada de sí misma en la mera "publicidad" del "uno", y una vida arriesgada a vivirse en la cercanía de la pregunta por el ser. Por ese camino nos veríamos obligados a pensar la artesanía y, por ende la cotidianidad, desde ellas mismas, y no en relación con otra cosa exterior a ellas. Pero, ¿cuál puede ser el camino para no derivar automáticamente en la perspectiva autosufi-

[11] Hay en especial un poema de Schiller que puede generar algún desconcierto, dado que es una interesante y fuerte reivindicación de la "Dignidad de las mujeres", pero igual cabe pensar que se trata de un recordatorio de cuál es su lugar; dice en una estrofa:

Pero con la mirada encantadora y fascinante

indican las mujeres el camino de regreso al fugitivo,

le aleccionan a volver hacia el presente.

En el modesto refugio de la madre

permanecen con pudorosa virtud

las hijas fieles de la inocente naturaleza.

(Schiller, 1998: 99-103).

THÉMATA. Revista de Filosofía, Nº51 enero-junio (2015) pp.: 247-270

doi: 10.12795/themata.2015.i51.13 
ciente y distanciada del saber teórico? Es claro que, en todo caso, es necesario renunciar de entrada a toda tentativa por tratar de mostrar, por ejemplo, que la artesanía es con toda legitimidad arte, tal como en cierto sentido puede desprenderse de las bienintencionadas tesis de Gadamer sobre el arte popular o de las de Danto sobre el "fin de la historia del arte". No puede olvidarse que la artesanía no es como tal objeto de un museo, por lo menos no en tanto que artesanía, aunque es verdad que puede "transfigurarse" en una obra de arte o ser una pieza etnográfica, pero en ambos casos deja de ser entonces lo que es. $\mathrm{Su}$ mundo propio es otro, es el mercado artesanal, y su destino, allí donde se realiza plenamente como lo que es, es la casa.

Aunque, de otro lado, no se trata sólo de reivindicar un positividad absoluta para el fenómeno de la artesanía, frente al que cabría decir que todo cuanto se ha dicho sobre ella es simplemente equivocado, más bien lo que se impone es preguntar por la verdad de lo que es dicho en tal pensar. Esto implica admitir que los juicios sobre la trivialidad y la insignificancia de la artesanía y de la cotidianidad no es que de suyo sean falsos, sino que la verdad que enuncian la hemos tomado de una manera apenas exterior. En consecuencia, no sólo admitiremos que la artesanía no es arte, sino que habremos de aceptar que es insignificante y trivial, pero no como si eso fuera la aceptación de su nulidad de sentido, sino, al contrario, la marca de su positividad y de su plenitud de sentido, como si nos preguntáramos cuál puede ser el significado de lo insignificante, o cuál puede ser el valor y la importancia de lo trivial. Lo que sugiero es entonces que los seres humanos no necesariamente caemos en la trivialidad y en la insignificancia por un descuido o porque estemos enajenados, sino que es algo perseguido como un auténtico logro. Puede parecer contraevidente querer sostener semejante idea, pero ello es sólo porque se nos ha hecho obvio e incuestionable lo contrario. Asumimos sin más, sin reflexionar sobre ello, que la cotidianidad sólo puede ser un punto de partida pero no un punto de llegada; sin embargo, habría que preguntar si la vida cotidiana es algo en sí mismo carente de importancia o si más bien por alguna razón nos hemos vuelto incapaces de valorarla como lo que es.

En ese intento por pensar la artesanía desde ella misma, es necesario pues admitir que es heterónoma; que para ella son esenciales el oficio, el trabajo de la manos, los materiales; que es modesta, no tiene la pretensión de trascender el tiempo y el espacio, ni tiene la profundidad espiritual e intelectual del arte; que está asociada a lo femenino, su esfera de realización es por excelencia la casa; y que se orienta eminentemente por una racionalidad práctica.

Sin embargo, ahora, éste ya no se presenta como el listado de cargos que se le hace desde la filosofía para dejarla de lado, ya no son los argumentos para demostrar su irrelevancia, sino que son los rasgos positivos que definen su esencia y en los que radica el sentido que la articula a la existencia humana, y que la hacen mucho más que apenas ineludible como si se tratara de un mal 
necesario. Es cierto que es heterónoma, pero quedarse en ese señalamiento no permite entender la transfiguración por medio de la cual un mero objeto útil es transmutado en un regalo, ya que a diferencia de la obra de arte, cuyo principio de producción es la creación original y la autonomía, la pieza artesanal se orienta por el principio general del cuidado, de ahí que el objeto artesanal sea el regalo por excelencia, no es algo simplemente útil, en abstracto, ni es tampoco bello sin más, sino siempre con relación a alguien y a una situación específica. Así mismo, se dice que es apenas oficio, pero retener sólo lo que ello implica desde el punto de vista del arte, impide reconocer que en la manera como el maestro se sumerge en su oficio acontece algo más parecido a una revelación que a un simple enajenamiento, se da aquí una particular relación entre el mero e indiferenciado "estar a la mano" y un tipo de distanciamiento que se parece al de la perspectiva teórica, en tanto que también la maestría en el oficio se alcanza sólo a partir de la experiencia del fracaso, del reconocimiento de la voluntad propia y de la resistencia que opone el material; el artesano tiene primero que reconocer la piedra como lo que ella es, sólo que ahora la posibilidad del reconocimiento no se da por el camino del distanciamiento teorético, donde el material es simplemente arrancado de la inmediatez de su "estar a la mano" sino, al contrario, por el de la inmersión, por una compenetración cada vez mayor del artesano con su oficio, con sus herramientas y con sus materiales, así, más que la contraposición entre el heideggeriano "estar a la mano" y el "estar a la vista", se trataría de algo así como "estar a la vista de la mano"; ojo y mano, inmediatez y distancia: el artesano ve con sus manos, con su cuerpo todo, y toca -talla, labra- con sus ojos. Además, cuando sólo se destaca la negatividad del oficio como un movimiento mecánico y repetitivo, igual que una máquina pero menos eficiente, se nos oculta que la misma repetibilidad es un paciente logro, y que más que una repetición abstracta, medible desde una concepción cuantitativa del tiempo, supone la aprehensión de un ritmo, es por lo tanto un modo del tiempo cargado en sí mismo de sentido, un tiempo propio. Y hemos dicho también que la artesanía es modesta, pero más que sólo insignificancia, ésta es la manera como puede cumplir algo fundamental: acompañar sin perturbar, poblar el mundo, llenar la casa, pero no en el sentido de abarrotarla, sino en el de constituirla como lo que es, en tanto que la funda y delimita, "espacia", como diría Heidegger, y mantiene así abierto un espacio en el que es posible el despliegue de la existencia humana. Por último, su supuesta irracionalidad habría que entenderla más bien como un tipo de racionalidad que desafía algunos de los ideales en los que se arraiga la concepción moderna de racionalidad; es un saber práctico para el que la verdad y la funcionalidad no están relacionadas con alguna aspiración a una universalidad abstracta, sino a la situación concreta, al uso, y para la que la producción de lo mismo es siempre la producción de otra cosa, en la que, en consecuencia, la perfección no está determinada por la repetibilidad y no está garantizada de antemano, sino que en cada caso se 
refiere a un logro específico; es más bien un horizonte que se va ensanchando y desplazando en la medida en la que, en virtud de su propio trabajo y de la transformación de los materiales, el artesano se transforma a sí mismo y deviene en maestro.

\section{VI.}

Demos un paso más. Pensemos la relación entre arte y artesanía, que sería también entonces entre vida del espíritu y cotidianidad, a la luz de los espacios emblemáticos que se les han atribuido desde la modernidad: el museo y la casa. Es cierto que el arte contemporáneo tal vez ya no quiere definirse a sí mismo en una relación exclusiva con el museo, quiere instalarse en el espacio público, pero esta nueva situación no necesariamente quiere decir que el arte haya aceptado "reducirse" a lo decorativo; incluso cuando Heidegger (2002), Gadamer (1997) o Vattimo (1997) nos hablan de la esencia decorativa del arte no están queriendo decir que el arte sea decoración, al igual que cualquier ornamento, sino que quieren destacar, en contra de la pretensión absolutista del concepto moderno de autonomía del arte, que la obra no puede ser abstraída del espacio, pero hay un abismo insalvable entre eso, que es un criterio teórico más bien abstracto, y admitir algunas de las consecuencias prácticas que podrían desprenderse de ello, como por ejemplo, que la obra siga siendo lo que es incluso en el caso de estar en el comedor de una casa, haciendo juego con las cortinas y los muebles. Porque es como si, de un modo análogo a lo que propone Danto respecto de la transfiguración del objeto ordinario, que al ser arrancado de su ámbito y llevado al museo o a la exposición deviene en obra de arte, también lo que es aceptado de suyo como obra de arte sufriera una transfiguración cuando se instala en el entorno cotidiano, en la casa.

Volvamos al principio, la artesanía entonces no se comprende adecuadamente cuando la queremos entender como lo otro del arte (o del diseño), ya sea que esto quiera decir un arte imperfecto, un arte falso, un arte que carece de espiritualidad (es sólo oficio), un arte popular, o que se la vea como el antecedente del arte; todas estas caracterizaciones negativas dependen de que se acepte describir la artesanía en función de las categorías o conceptos propios del arte, tales como autonomía, creatividad, genio, obra, espectador, belleza, etc. Por supuesto, hay que admitirlo, también depende de que se siga aceptando una, ya bien revaluada, concepción estetizante del arte, la que, para decirlo con Gadamer, sigue atrapada en la distinción estética propia de la conciencia estética.

Es cierto que ya Heidegger, Collingwood, Gadamer y Danto, entre muchos otros pensadores contemporáneos, han hecho una convincente y acertada crítica de tal concepción, y han mostrado que el concepto de arte está referido a unos "fundamentos antropológicos"; pero es como si persistiera el recurso 
de idealizar el arte, de objetivarlo o cosificarlo, como si no acabáramos de salir de una cierta religión del arte que fija los criterios definitivos en función de los cuáles debe evaluarse la excelencia, espiritualidad y racionalidad de toda producción humana. En tal sentido, sería también equivocado asumir que comprender adecuadamente la artesanía signifique aislarla y entenderla como un ente autónomo, con un sentido positivo frente al sentido positivo del arte, donde, como dice Bourdieu, se reivindique para ella una especie de estética inversa; el punto es más bien entenderla en función de un horizonte o de una red de relaciones en la que simplemente ella constituye una condensación, entenderla, en suma, en el horizonte de la vida cotidiana, de la casa, del saber práctico y de una, digamos, mística de la vida (antes que de una mística de la trascendencia, de la muerte o de la nada). No se puede negar que la propuesta de Gadamer apunta en esa misma dirección con su crítica a la noción cosificadora de "obra" y al proponer como fundamentos antropológicos del arte el juego, el símbolo y la fiesta; pero se queda corto, tal vez porque busca reconciliar el concepto más clásico de arte con la dimensión más intelectualizada y artificial del arte contemporáneo, y así incurre en una cierta idealización e intelectualización del concepto más clásico de arte que lo lleva a pensar en la conciencia estética como una pura distorsión, como el velo que impide captar la continuidad entre lo que denomina el gran arte del pasado y el actual, cuando bien pudiera ser precisamente el puente, algo hasta cierto punto perseguido, una consecuencia, aunque no necesariamente la culminación y plena realización. En relación con esto considero más conveniente el punto de vista de Blumenberg, que nos permite desplazar hacia el pasado la pregunta por la conciencia estética y, con ello, establecer un vínculo entre dicha conciencia y el sentido más originario del logos. Y no es que Blumenberg simplemente valide otra vez la distinción y la conciencia estética tan cuestionada por Gadamer, sólo que no la entiende como el obstáculo que de suyo impide comprender la dimensión racional del arte, dimensión que no se agota, como en Kant, en el mero juego formal de las facultades del entendimiento, sino que, por el contrario, apunta al sentido más originario del logos.

El camino seguido por Gadamer conduce a una idealización de la artesanía, entendida en el sentido restringido de arte popular ${ }^{12}$; el de Blumenberg,

[12] Conviene aquí hacer una precisión, frente a un comentario que me hizo el profesor Javier Domínguez. Según él, tal vez mi tesis debería anunciarse como referida en general a los utensilios o al arte popular y no al concepto más bien difuso de "artesanía"; y no le falta algo de razón, pero entonces habría que aclarar que no a cualquier tipo de utensilio sino específicamente a aquellos que son hechos a mano, cuya función es eminentemente decorativa (aunque no necesariamente por ello riñen con la funcionalidad) y que, además, han venido a ganar, sobre todo en nuestros días, una valoración y consideración estética, al punto de que algunos han dicho de ella que se trata de una falsificación del arte, de algo que tiene la apariencia engañosa del arte, y otros han querido reivindicarla como arte legítimo. Así, pese a la amplitud que de suyo tiene el término "artesanía", lo cierto es que en nuestro medio la palabra se ha lexicalizado en un sentido particular y habitual-

THÉMATA. Revista de Filosofía, No51 enero-junio (2015) pp.: 247-270 doi: 10.12795/themata.2015.i51.13 
en cambio, nos permite desidealizar, mejor desmitificar, tanto el arte como el arte popular, y formular con toda legitimidad la pregunta por el sentido de la

mente se la usa sin mayores precisiones para referirse a objetos hechos a mano, que tienen una dimensión estética y una carga de identidad cultural; en algunos casos ha primado la consideración estética y entonces se habla sólo de la artesanía como decoración, en otros ha primado el rasgo de la identidad cultural y entonces se habla de arte popular. En lo que sigue, pues, nos estaremos refiriendo a la artesanía en ese sentido, en el de un tipo particular de utensilios y objetos decorativos que acompañan la vida cotidiana y que en ocasiones adquieren la connotación de arte popular.

Habría que concederle al profesor Domínguez que la categoría de arte popular puede ser mucho más adecuada y precisa, pero tiene un inconveniente, de entrada nos circunscribe al ámbito abierto por el concepto moderno de arte, y nuestro interés ahora no es tanto el de ampliar dicho concepto como el de cuestionar la primacía metodológica de él en la tarea de comprender la especificidad de la artesanía; es claro, por ejemplo, que si el oficio ha devenido inesencial para el arte (y nuestro interés ahora no es entrar a negarlo o discutirlo) entonces la pregunta por el oficio o el trabajo manual desde ahí ya estaría determinada previamente, de modo que la salida sólo pudiera consistir en proponer una tesis de alcance igual de universal: reivindicar otra vez la condición esencial del oficio para el arte y caer en el juego estéril de afirmar algo así como la falsedad de todo arte conceptual y sostener que el arte verdadero es sólo aquel para el que sigue siendo esencial el oficio. Aunque pudiera ser que la inesencialidad del oficio para el arte no signifique su liquidación o el reconocimiento de un error sino más bien, en un sentido hegeliano, su "superación", algo así como que el oficio habría dejado de ser el único referente en virtud del cual se define la verdad o la esencia del arte, como si dijéramos que el arte, en tanto que oficio, pertenece al pasado; en esta dirección tal vez no hubiera que acudir a la drástica medida de volver a reivindicar la esencialidad del oficio para el arte, pero, con todo, se nos bloquearía el acceso a la pregunta por la dimensión de verdad y espiritualidad del oficio o nos obligaría a pensar que la persistencia del oficio sólo puede entenderse como anacronismo.

En suma, hay una ventaja metodológica en no restringirnos a la noción de arte popular: ello nos permite, de un lado, preguntar por la espiritualidad del oficio, así esto parezca en un primer momento que la reflexión se limita a ese pasado en el que el oficio pudo ser esencial, a ese período en el que el arte en general era de suyo arte popular (cabría decir que las nociones hegelianas de arte simbólico y clásico son desde esta perspectiva arte popular); pero, de otro lado, y en vistas del reconocimiento de la superación de su necesidad (verificable tanto respecto del arte como de la producción industrial de objetos cotidianos), nos permite preguntar por su impresionante persistencia en nuestros días, que difícilmente se podría entender sólo como anacronismo, como una especie de pugna entre modernidad y tradición, o como el resultado de esa ampliación y pluralización de horizontes del espíritu moderno, donde el oficio sobrevive como una entre otras posibilidades de la verdad sin tener ya el carácter definitivo y único que tuvo en el pasado, porque entonces, sin negar que ello es cierto, nos veríamos enfrentados a otra disyuntiva predeterminada por la primacía del arte, donde otra vez, por así decirlo, sale perdiendo la artesanía, ya que al arte le correspondería el privilegio del pluralismo y el cosmopolitismo de la sociedad secular moderna y la artesanía cargaría con el estigma de lo local, tradicional y etnocéntrico, cuando el punto es que precisamente la alta valoración que ha ganado la artesanía se corresponde propiamente a ese mundo secular moderno, a ese mundo masificado, globalizado, multicultural y lleno de turistas. Digámoslo de una vez, la tesis que se quiere sostener es que la persistencia de la artesanía no se entiende sólo en términos de pluralización, no es sólo que ahora sobreviva como una posibilidad entre otras en un mundo para el que cualquier cosa puede ser arte, sino que, sobre todo y sin que se quiera negar la verdad de lo anterior, su persistencia nos habla de un rasgo constitutivo de la condición humana, no sólo de lo que marca la diferencia en las cosmovisiones de este o aquel pueblo o de un determinado momento de la historia, sino antes bien de lo común, de algo que nos permite hablar de una cierta continuidad y permanencia de lo humano: seguimos siendo hombres de las cavernas, pero precisamente porque ya el cavernícola es también ilustrado.

THÉMATA. Revista de Filosofía, №51 enero-junio (2015) pp.: 247-270

doi: 10.12795/themata.2015.i51.13 
cotidianidad, esa en la que nos encontramos con la modesta e intrascendente artesanía, porque ya no se parte de la vida cotidiana simplemente como lo dado, sino a la vez como un altísimo logro.

Sigamos entonces por este camino, por el de pensar la artesanía en el horizonte de la vida cotidiana, en el que, por excelencia, la encontramos circunscrita al ámbito de la casa, de modo que la indagación por ésta podrá decirnos algo acerca de la artesanía.

La cotidianidad se define en virtud de la casa y la tranquilidad que ofrece. Se dice, por ejemplo, que "uno se siente como en casa", en eso radica la vida cotidiana, en el arraigo, en la confianza; sin embargo, la existencia humana no es posible únicamente adentro, todo el tiempo estamos obligados al desarraigo, a enfrentar el afuera, lo desconocido, lo extraordinario, pero adentro y afuera no son apenas eso, no son meros referentes espaciales absolutos definidos por su oposición, el adentro no es sólo un refugio o una madriguera, es nuestro hogar, es nuestro espacio, el referente nuclear de lo que denominamos mundo ${ }^{13}$; y a su vez el afuera lo es respecto de la casa; de otro lado, realmente, y pese a todo, nunca podemos estar de manera definitiva en el afuera, todo salir de la casa implica constitutivamente la promesa o la esperanza del regreso, y es sólo en virtud de ello que se trata como tal de un salir; de ahí que estrictamente el único que puede "entrar" o "salir" es el ser humano, el animal a lo sumo se refugia en una madriguera, pero no "vive" en ella, no la habita. Ahora bien, esa promesa o esa esperanza se hace visible en algo que tal vez pudiera servir para describir fenomenológicamente lo que somos: una maleta, una mochila, unos bolsillos, una cartera; siempre cargamos algo, como si además de ser un animal dotado de lenguaje, nos pudiésemos definir como un animal con mochila; y la llevamos bien sea como una especie de memoria de la casa, de certificación de nuestra promesa de regresar a ella, o bien para poder llevar a casa lo que cosechamos afuera, porque cuando salimos no es sólo para buscar sustento y provisiones, sino para llevar este sustento y provisiones a la casa.

El animal que carece de la expectativa del regreso y del horizonte originario o a veces ideal de la casa, no requiere mochila. Así pues, la casa y la cotidianidad son lo que son en relación con el afuera y lo extraordinario, la casa es entonces origen y destino, todo salir de ella está marcado por la expectativa del regreso, de ahí también la condición esencial y simbólica de la puerta.

La vida dentro de la casa es tranquila y segura. La casa es, como diría Blumenberg (2003), el ámbito del absolutismo de los deseos y de la razón soberana. Sin embargo, en cuanto a lo primero, no puede ser por sí sola la esfera de su realización y, en cuanto a lo segundo, se trata de una razón que no conoce límites y está por lo mismo extraviada en meras ilusiones. Es necesario salir

[13] Para desarrollar este tema me he orientado sobre todo por los estudios fenomenológicos de Bachelard (1975) y de Bollnow (1969).

THÉMATA. Revista de Filosofía, No51 enero-junio (2015) pp.: 247-270 doi: 10.12795/themata.2015.i51.13 
de la casa, sólo afuera es posible la satisfacción plena del deseo pero, a la vez, afuera la voluntad y la razón se enfrentan a su límite y a su negación, afuera están los peligros, la inclemencia de una realidad omnipotente y cuya voluntad es absoluta, pero también están los alimentos y sobre todo la oportunidad para que esa razón meramente extraviada en sí misma devenga propiamente razón, y lo consigue cuando, al enfrentarse a su límite, logra ponerle un velo: lo nombra, y con ello no sólo consigue tomar distancia y abrir así un claro en el que puede desplegarse la existencia humana, sino también tejerlo a su propio horizonte. El nombre es además la historia de un encuentro en el que si bien no se relata la derrota definitiva de la realidad, si la estratagema con la que, digamos así, se consiguió engañarla; y eso es en lo fundamental lo que llamamos mito. Pero la potencia del mito, su eficacia para contener el absolutismo de la realidad, depende precisamente de que se lo narre, así, todo lo que acontece afuera sólo gana el sentido de lo extraordinario en tanto se transfigure en una historia que se puede contar en la tranquilidad de la casa. Ahora bien, la importancia de tales historias en la vida cotidiana no debe confundirse con algo como la importancia que pudiera tener hoy un televisor, no se trata de un entretenimiento para escabullirse del embotamiento y aburrimiento de la cotidianidad, si en realidad fuera eso, entonces sería justificada la pretensión de querer vivir toda la existencia arrojado a la aventura y a lo extraordinario, ¿por qué habría que soportar así fuera un minuto de aburrida vida cotidiana? Lo que se narra, es decir el mito, no es apenas una aventura en el sentido estético que ha llegado a ganar la expresión a partir de una estética de la vivencia, se trata más bien, digámoslo así, de una cosmogonía, en la que el relato da cuenta, es a la vez testimonio y garantía, del modo como ha sido posible abrir un claro en el medio de lo desconocido, del ensanchamiento de los límites del hogar. Pero no está primero la casa y luego las historias, la casa es de suyo la realización concreta del distanciamiento frente al absolutismo de la realidad y en esa misma medida es fundación del espacio en el que se levanta, porque el espacio, y en consecuencia la casa, sólo es lo que es en tanto que memoria; es por el distanciamiento logrado desde el mito que es posible la casa, y a la inversa, porque el espacio sólo deviene en tanto que tejido por el tiempo. Una casa, o una ciudad entera, se derrumban cuando se desvanece la memoria; no es el paso inexorable del tiempo lo que corroe, es el olvido, la ausencia de tiempo, la imposibilidad de las historias. La narración no es pues un inventario de aventuras, sino que es fundación, en ella el tiempo se hace propiamente el tiempo en tanto que referido a la existencia, y el horror por lo absolutamente desconocido es mantenido a raya bajo la máscara del nombre.

Así pues, al indagar por el entorno en el que la pieza artesanal se realiza como lo que es, la casa, nos encontramos con el mito, y por lo mismo tal vez entonces no es gratuito que mito y artesanía sean conceptos que han corrido una suerte muy similar en la interpretación que de ellos se ha hecho desde la 
modernidad ilustrada, ambos se han asociado a una visión premoderna y preilustrada, y han sido descalificados en tanto que irracionales. El mito, como la artesanía, está vinculado a la casa, al igual que ella es abrigo y es límite. Su función sólo se entiende a partir de la tensión irresoluble de la existencia humana entre el afuera y el adentro. Según Blumenberg, en la frontera, apenas imaginable de la experiencia originaria de horror de una existencia sometida a la inclemencia del afuera, enfrentada a la voluntad todopoderosa y absoluta de una realidad totalmente desconocida (y que en tanto tal es precisamente horrorosa), nos encontramos con la caverna y con el mito, pero entonces es porque ya ese absolutismo de la realidad ha sido relativizado y de él sólo podemos saber algo en virtud del distanciamiento y enmascaramiento en el que se muestra a partir de la palabra que lo nombra, o del que posibilita el refugio de la caverna. Así que ambos, caverna y mito, son ya una superación que evidencia el trabajo del logos, porque se ubican del lado de acá, y son prueba de que ya la existencia no se encuentra a merced del horror y sometida a la voluntad absoluta de la realidad; la primera estrategia del logos para enfrentar lo desconocido es darle nombres, es hacerlo soportable y visible desde el velo de la palabra.

El mito, entonces, no es un relato falso, es un tomar distancia, es una racionalización de la experiencia, es un esfuerzo por comprender lo incomprensible, una interpretación que define como tal cualquier posible sentido posterior del logos; el mito mismo es desmitologizador. Así, las distintas interpretaciones históricas acerca del sentido del mito hacen parte de la historia del mito, no son una toma de distancia y el logro de una objetivación, sino una continuación de la tarea originaria del logos: interpretar, seguir interpretando indefinidamente. Con el mito, el absolutismo de la realidad estalla y el mundo se puebla de dioses y demonios con los que, para bien o para mal, es posible tratar, se puede razonar. La realidad, en su muda omnipotencia, en su, digamos "absolutidad", es intratable, de modo que el mito, antes que lo opuesto a la razón, es lo que la hace posible.

Lo que hemos ganado hasta aquí es un camino para pensar la artesanía desde ella misma en virtud de su cercanía con el mito, de su habitar la casa y en el horizonte de lo femenino; y esto nos permite sacarla de esa línea de continuidad que inicia con la producción precaria de herramientas de caza, continúa con templos monumentales y esculturas en piedra y desemboca en la creación de obras de arte y en los productos del diseño industrial, para verla más bien desde la perspectiva de la operatividad del logos, esto es, en relación con las estrategias por medio de las cuales se mantiene a raya el absolutismo de la realidad, y se preserva así en lo abierto el espacio, y el tiempo, en el que es posible la existencia.

Por este camino se nos ratificaría lo inadecuado de seguir pensando la artesanía como el antecedente del arte y, de otro lado, se reivindicaría su racionalidad, pero no en un sentido disminuido, sino más bien en el sentido 
más originario que podría tener este concepto y que nos permite dotar de un significado más pleno la idea de una profunda continuidad de lo humano. Y no se malentienda esto como una recaída en la tentación metafísica, porque de lo que se trata es de arraigar esa continuidad en la cotidianidad, en el horizonte de la construcción y habitación de la casa, así como en relación con la tensión entre el afuera y el adentro, entre lo cotidiano y lo extraordinario; y, a la vez, de entender la cotidianidad desde la perspectiva más amplia de las estrategias para mantener a raya el absolutismo de la realidad. Lo que perseguimos los seres humanos todo el tiempo, y es en ello en lo que en un sentido profundo consiste ser racionales y se cifra la continuidad de lo humano, es hacer familiar y cotidiano lo extraordinario, es ensanchar y preservar los límites de lo cotidiano; el heroísmo y lo extraordinario siempre acontecen en el camino a casa, y son lo que son sólo porque vamos a casa.

La artesanía se puede definir entonces como el correlato plástico del mito, ella misma es ya un rendimiento del logos, así como de la autonomía y de la conciencia estética. Apropiándonos de las ideas de Blumenberg podemos decir que en esa zona fronteriza del absolutismo de la realidad, donde el mito es ya una superación de ese horror original, la artesanía es ya una superación del carácter amorfo e indiferenciado de la realidad sensible; la autonomía y la conciencia estética son un correlato de una autonomía de la realidad despotenciada, desabsolutizada. El trabajo estético consiste en despotenciar a la realidad de cualquier carga o sustrato significativo absoluto.

En la tarea originaria de racionalizar la angustia como miedo, en esa situación de tensión entre el absolutismo de la realidad y el absolutismo de los deseos, la artesanía es uno de los artificios que permite, plásticamente, individualizar la totalidad y configurar múltiples formas de lo amorfo, de modo que una realidad de múltiples formas diferenciadas sirva para velar u ocultar el horror de una realidad absoluta, única e indiferenciada. Desde la perspectiva de la racionalidad, la artesanía es, como diría Blumenberg, una muestra de muchos quilates del trabajo del logos.

Tal vez, entonces, no sea exagerado pensar, en su conjunto, la historia occidental en virtud de la tensión, el equilibrio y el desequilibrio, entre lo cotidiano y lo extraordinario. Ha sido una cultura fascinada por lo extraordinario, de ahí por ejemplo la filosofía, piénsese en la exaltación que hace Platón del afuera y en su condena de la caverna; de ahí la modernidad, cuyo inicio se podría fechar con la decisión de Colón de aventurarse en los mares de lo extraordinario; y de ahí también el arte, simbólicamente caracterizado por su renuncia al taller del artesano, el artista es alguien que se va de la casa. En consecuencia, quizá pudiera caracterizarse la llamada por algunos posmodernidad como la época de la rememoración de la casa: Odiseo quiere volver a Ítaca.

Caverna, mito y artesanía entrelazados. Somos cavernícolas que contamos historias; y hacer la casa se confunde y es una con la narración de his- 
torias; el tiempo se hace tiempo en las manos, en el barro y en el torno del alfarero; el tiempo hunde sus raíces en el espacio, en el cuerpo, y sólo entonces se yergue y se hace historia; el espacio a su vez se funde con el tiempo, es decir con la historia, y se hace casa, es decir espacio propiamente. Penélope teje y desteje, Odiseo se olvidó de su casa, pero ahí está su cama, la que construyó con sus manos, porque primero fue artesano antes que héroe. 


\section{Referencias bibliográficas:}

Aicher, Otl (2001). Analógico y digital. Yves Zimmermann (trad.). Barcelona: Gustavo Gili.

(1994). el mundo como proyecto [todo en minúscula en el original]). Joaquín Chamorro Mielke (trad.). Barcelona: Gustavo Gili.

Bachelard, Gaston (1975). La poética del espacio. Ernestina de Champourcin (trad.). México: F. C. E.

Blumenberg, Hans (2003). Trabajo sobre el mito. Pedro Madrigal (trad.). Barcelona: Paidós.

Bollnow, Otto Friedrich (1969). Hombre y espacio. Jaime López de Asiaim (trad.). Barcelona: Labor.

Bordieu, Pierre (1988). La distinción. Criterios y bases sociales del gusto. María del Carmen Ruiz de Elvira (trad.). Madrid: Taurus.

Canclini, Néstor G. (2001). Culturas híbridas: estrategias para entrar y salir de la modernidad. Buenos Aires: Paidós.

Collingwood, R. G. (1960). Los principios del arte. México: F. C. E.

Danto, A. (2003). Más allá de la caja Brillo. Las artes visuales desde la perspectiva posthistórica. Alfredo Brotons Muñoz (trad.). Madrid: Akal.

Dorfles, Gillo (1977). El devenir de las artes. Roberto Fernández Balbuena (trad.). Bogotá: F.C.E.

Ferrier, Jean Luis (1975). La forma y el sentido. Mercedes Rivero (trad.). Caracas: Monte Ávila.

Gadamer, Hans-Georg (1991). La actualidad de lo bello. Antonio Gómez Ramos. (trad.). Barcelona: Paidós.

Verdad y método I (1997). Ana Agud y Rafael de Agapito (trad.).

Salamanca: Sígueme.

Gombrich, E. H. (1999). El sentido del orden. Estudio sobre la psicología de las artes decorativas. Esteve Riambau (trad.). Madrid: Debate.

Heidegger, M. (1958). Arte y poesía. Samuel Ramos (trad.). México: F. C. E.. (1994). Conferencias y artículos 5. Eustaquio Barjau (trad.). Barcelona: Ediciones del Serbal. (2002). El arte y el espacio. Félix Duque (trad.). Pamplona: Universidad Pública de Navarra. (2003). Ser y tiempo. Jorge Eduardo Rivera (trad.). Madrid: Trotta.

Herrera, Neve (1996). Listado general de oficios artesanales. Bogotá: CENDAR

Lauer, Mirko (1982). Crítica de la artesanía. Plástica y sociedad en los Andes peruanos. Lima: Centro de estudios y de promoción del desarrollo,

Loos, Adolf (1972). Ornamento y delito y otros escritos. Lourdes Cirlot y Pau Pérez (trad.). Barcelona: Gustavo Gili. 
Mayr, Franz (1989). La mitología occidental. Barcelona: Anthropos.

Panofsky, E. (1987). Idea: contribución a la historia de la teoría del arte. María Teresa Pumarega (trad.). Madrid: Cátedra.

Riegl, Alois (1980). Problemas de estilo: fundamentos para una historia de la ornamentación. Federico Miguel Saller (trad.). Barcelona: Gustavo Gili.

Ruskin, John (1910). Las siete lámparas de la arquitectura. Carmen de Burgos (trad.). Valencia: F. Sempere y Compañía Editores.

Schiller, Friedrich (1998). Poesía filosófica. Daniel Innerarity (trad. e introd). Madrid: Hiperion.

Summers, David (1993). José Miguel Esteban Cloquell (trad.). El juicio de la sensibilidad. Renacimiento, naturalismo y emergencia de la estética. Madrid: Tecnos.

Tatarkiewicz, Wladyslaw (1991). Historia de la estética. (T. III). Danuta Kursyka (trad.). Madrid: Akal.

Vasari, Giorgio (2000). Vidas de los más excelente pintores, escultores y arquitectos (1570). Julio Payró (trad.). Barcelona: Océano.

Vattimo, Gianni (1997). El fin de la modernidad. Nihilismo y hermenéutica en la cultura posmoderna. Alberto L. Bixio (trad.). Barcelona: Gedisa, (6 $6^{\text {a }}$ reimpresión). 